UNIVERSIDADE DE SÃO PAULO

FACULDADE DE ECONOMIA, ADMINISTRAÇÃO E CONTABILIDADE DE RIBEIRÃO PRETO

DEPARTAMENTO DE ECONOMIA

PROGRAMA DE PÓS-GRADUAÇÃO EM ECONOMIA

ÁREA: ECONOMIA APLICADA

Ana Paula Alves Vieira

\title{
Como os países definem as metas para a inflação? Evidências em painel
}

Orientador: Prof. Dr. Fábio Augusto Reis Gomes 
Prof. Dr. Vahan Agopyan

Reitor da Universidade de São Paulo

Prof. Dr. Dante Pinheiro Martinelli

Diretor da Faculdade de Economia, Administração e Contabilidade de Ribeirão Preto

Prof. Dr. Renato Leite Marcondes

Chefe do Departamento de Economia

Prof. Dr. Sergio Naruhiko Sakurai

Coordenador do Programa de Pós-Graduação em Economia - Área: Economia Aplicada 


\section{Ana Paula Alves Vieira}

\section{Como os países definem as metas para a inflação? Evidências em painel}

Dissertação de Mestrado apresentada ao Programa de Pós-Graduação em Economia - Área: Economia Aplicada da Faculdade de Economia, Administração e Contabilidade de Ribeirão Preto da Universidade de São Paulo, para obtenção do título de Mestre em Ciências. Versão corrigida. A original encontra-se disponível na FEA$\mathrm{RP} / \mathrm{USP}$.

Área de concentração: Macroeconomia

Orientador: Prof. Dr. Fábio Augusto Reis Gomes 
Autorizo a reprodução e divulgação total ou parcial deste trabalho, por qualquer meio convencional ou eletrônico, para fins de estudo e pesquisa, desde que citada a fonte.

Vieira, Ana Paula Alves

Como os países definem as metas para a inflação? Evidências em painel./Ana Paula Alves Vieira. - 2018.

43 páginas

Dissertação (Mestrado) - Faculdade de Economia, Administração e Contabilidade de Ribeirão Preto/USP. Área de Concentração: Macroeconomia

Orientador: Prof. Dr. Fábio Augusto Reis Gomes

1. Metas para a Inflação

2. Política Monetária

3. Dados em Painel 


\title{
Como os países definem as metas para a inflação? Evidências em painel
}

\author{
Dissertação para obtenção do grau de mestre apresentada à FEA- \\ RP/USP. Área de concentração: Macroeconomia \\ E aprovada em: 30/05/2018 \\ Pela comissão organizadora
}

Prof. Dr. Fábio Augusto Reis Gomes, (Orientador)

FEA-RP/USP

$\overline{\text { Prof. Dr. Eurilton Alves Araújo Júnior }}$ Banco Central do Brasil

Prof. Dr. Cleomar Gomes da Silva PPGE/UFU

Prof. Dr. Luciano Nakabashi

FEA-RP/USP 
Success consists of going from failure to failure without loss of enthusiasm.

- Winston Churchill 
VIEIRA, A. P. A. Como os países definem as metas para a inflação? Evidências em painel. Dissertação (Mestrado) - Faculdade de Economia, Administração e Contabilidade de Ribeirão Preto, Universidade de São Paulo, 2018.

\section{Resumo}

Este trabalho analisa como a meta para a inflação é definida pelos países adeptos deste regime monetário. Pretende-se investigar se os fundamentos macroeconômicos determinam as metas, isto posto, existiria uma evidência de que os países adotam uma estratégia gradualista de política monetária. Neste estudo, os fundamentos são medidos pela inflação, dívida bruta como proporção do PIB (estoque e fluxo) e taxa de crescimento do PIB real. Usando dados em painel desbalanceado e dados cross-section estima-se os determinantes das metas para a inflação para países avançados e emergentes via Mínimos Quadrados Ordinários, Efeito Fixo e Efeito Aleatório. Verifica-se que um nível de preços estável está associado a uma meta mais ambiciosa, assim como a adoção de bandas de tolerância contribui para uma meta mais baixa. Outros resultados sugerem que não se pode afirmar que uma política fiscal sustentável é importante para os formuladores das metas e que países emergentes, cujos fundamentos macroeconômicos, em geral, são piores comparados aos de países avançados, apresentam uma meta mais alta para a inflação. Além disto, verifica-se que um crescimento elevado e robusto está associado a uma meta mais baixa. Sendo assim, existem evidências de que os países adeptos do regime de metas adotam uma estratégia gradualista de política monetária.

Palavras-chave: Metas para a Inflação, Política Monetária, Dados em Painel 
VIEIRA. A. P. A. How do countries set their inflation targets? Panel evidence. Dissertation (Master Degree) - School of Economics, Business Administration and Accounting at Ribeirão Preto, University of São Paulo, 2018.

\begin{abstract}
This article analyzes how inflation target is set by inflation targeters. The aim is to investigate if the macroeconomic fundamentals determine the targets, that is, there would be evidence that countries adopt a gradualist monetary policy strategy. In this study, the fundamentals are measured by inflation, gross debt as a percentage of GDP (stock and flow) and real GDP growth rate. Using unbalanced panel data and cross-section data, the determinants of inflation targets for advanced and emerging countries are estimated using Ordinary Least Squares, Fixed Effect and Random Effect. It is found that a stable price level is associated with a more ambitious target, as the adoption of tolerance bands contribute to a lower target. Other results suggest that a sustainable fiscal policy can not be said to be important for policymaker and that emerging countries, whose macroeconomic fundamentals are generally worse than those of advanced countries, have a higher inflation target. In addition, it is found that more robust growth is associated with a lower target. Therefore, there are evidences that inflation targeters adopt a gradualist monetary policy strategy.
\end{abstract}

Keywords: Inflation Targeting, Monetary Policy, Panel Data 


\section{Lista de Figuras}

1.1 Meta central e o ponto médio da banda alvo. . . . . . . . . . . . . . 13

1.2 Histórico das metas para a inflação para os países da América Latina. . . . . . . 15

2.1 Metas altas e baixas para a inflação. . . . . . . . . . . . . . . . . . 23

A.1 Estimação dos Determinantes das Metas para a Inflação - Coeficientes obtidos ano a ano para a inflação. . . . . . . . . . . . . . . . . 38

A.2 Estimação dos Determinantes das Metas para a Inflação - Coeficientes obtidos ano a ano para a taxa de crescimento do produto real. . . . . . . . . . . . . 39

A.3 Estimação dos Determinantes das Metas para a Inflação - Coeficientes obtidos ano a ano para o estoque da dívida bruta. . . . . . . . . . . . . . . . . 40

A.4 Estimação dos Determinantes das Metas para a Inflação - Coeficientes obtidos ano a ano para o fluxo da dívida bruta. . . . . . . . . . . . . . . . 41

A.5 Estimação dos Determinantes das Metas para a Inflação - Coeficientes obtidos ano a ano para a dummy de bandas de tolerância. . . . . . . . . . . . . . . 42

A.6 Estimação dos Determinantes das Metas para a Inflação - Coeficientes obtidos ano a ano para a dummy de países emergentes. . . . . . . . . . . . . 


\section{Lista de Tabelas}

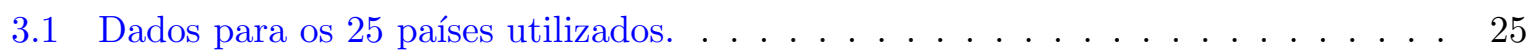

3.2 Descrição dos dados. . . . . . . . . . . . . . . . . . . 25

3.3 Hipóteses a serem testadas. . . . . . . . . . . . . . . . 27

4.1 Estimação dos Determinantes das Metas para a Inflação (a partir do ano de adoção do regime). . . . . . . . . . . . . . . . . . . . . . . . 29

4.2 Estimação dos Determinantes das Metas para a Inflação: Dummies para Bandas de Tolerância e para Países Emergentes (a partir do ano de adoção do regime). 30

4.3 Estimação dos Determinantes das Metas para a Inflação (período entre 2000-2016). 31

4.4 Estimação dos Determinantes das Metas para a Inflação: Dummies para Bandas de Tolerância e para Países Emergentes (período entre 2000-2016). . . . . . . . . 32 


\section{Sumário}

$\begin{array}{ll}\text { Lista de Figuras } & 9\end{array}$

$\begin{array}{ll}\text { Lista de Tabelas } & 10\end{array}$

$\begin{array}{ll}\text { Sumário } & 11\end{array}$

1 Introdução 12

2 Revisão de Literatura $\quad 16$

2.1 Viés Inflacionário $\ldots \ldots \ldots \ldots \ldots \ldots \ldots \ldots$

2.2 Caracterização do Regime de Metas para a Inflação . . . . . . . . . . . . . . . . . 18

2.2.1 Pré-condições para a adoção do regime de metas inflacionárias . . . . . . 19

2.2 .2 Como a meta para a inflação é definida? . . . . . . . . . . . . . . . . . . 21

3 Dados e Metodologia Empírica 23

4 Resultados $\quad 27$

5 Conclusão 33

$\begin{array}{ll}\text { Referências Bibliográficas } & 35\end{array}$

$\begin{array}{ll}\text { A Apêndice } & 38\end{array}$ 


\section{Capítulo 1}

\section{Introdução}

A literatura empírica relacionada aos sistemas de metas para a inflação busca, via de regra, responder questões a respeito da efetividade destes sistemas, em especial, em reduzir a inflação. Por exemplo, para economias emergentes, Gonçalves and Salles (2008) observam que países que adotam o regime de metas experimentam maior queda na inflação e na volatilidade do produto quando comparados aos países que não são adeptos do regime. Embora haja uma relação entre o regime de metas e uma baixa inflação, Brito and Bystedt (2010) verificam uma fraca correlação para economias emergentes e encontram uma relação negativa significante entre a adoção do regime de metas e o crescimento do produto. Para economias avançadas, Ball and Sheridan (2005) não encontram evidências de que a adoção de metas para a inflação melhora a performance macroeconômica destes países, enquanto que Carvalho and Gonçalves (2007) mostram a capacidade que estes países adeptos do regime de metas têm para reduzir a inflação com menores custos. Deste modo, ainda não há um consenso em relação ao desempenho inflacionário e ao crescimento do produto destas economias após a implementação do regime. De todo modo, é importante destacar que os resultados destes estudos são baseados em períodos amostrais, grupo de países e metodologias distintos.

Mesmo entre os países que adotam o regime de metas, há uma heterogeneidade no que tange às características do desenho institucional do regime, isto é, em relação à escolha do horizonte temporal para a convergência das expectativas de inflação para a meta, quanto à adoção de uma meta pontual ou intervalar e ao seu valor numérico, quanto à utilização de cláusulas de escape e, por fim, quanto à independência do banco central para perseguir a meta. Esta heterogeneidade é ilustrada por meio da Figura 1.1 que apresenta as metas pontuais e bandas de tolerância para 25 países em 2016. Repare que, para países emergentes, o ponto médio das metas intervalares são mais dispersos e a amplitude destes intervalos são maiores, ambos comparados aos países avançados. 
Uma meta pontual para a inflação pode ser mais efetiva no ancoramento das expectativas inflacionárias ao comunicar ao público um maior comprometimento em atingir a meta anunciada para a inflação do que bandas de tolerância, mas pelo elevado grau de rigidez, a política monetária perde integralmente seu caráter acomodatício na presença de choques negativos. Já as bandas de tolerância possibilitam ao banco central acomodar choques exógenos inesperados, mas sinalizam um controle impreciso da inflação. Uma solução para isto, conforme adotado por muitos países, é definir um intervalo em torno de um ponto médio, em que o objetivo de médio prazo é indicado pela meta central, podendo o banco central trafegar entre os limites deste intervalo no curto prazo a medida que a economia estiver sujeita à incertezas. Isto pode permitir um ancoramento das expectativas inflacionárias no longo prazo (Heenan et al. (2006)).

Figura 1.1: Meta central e o ponto médio da banda alvo.

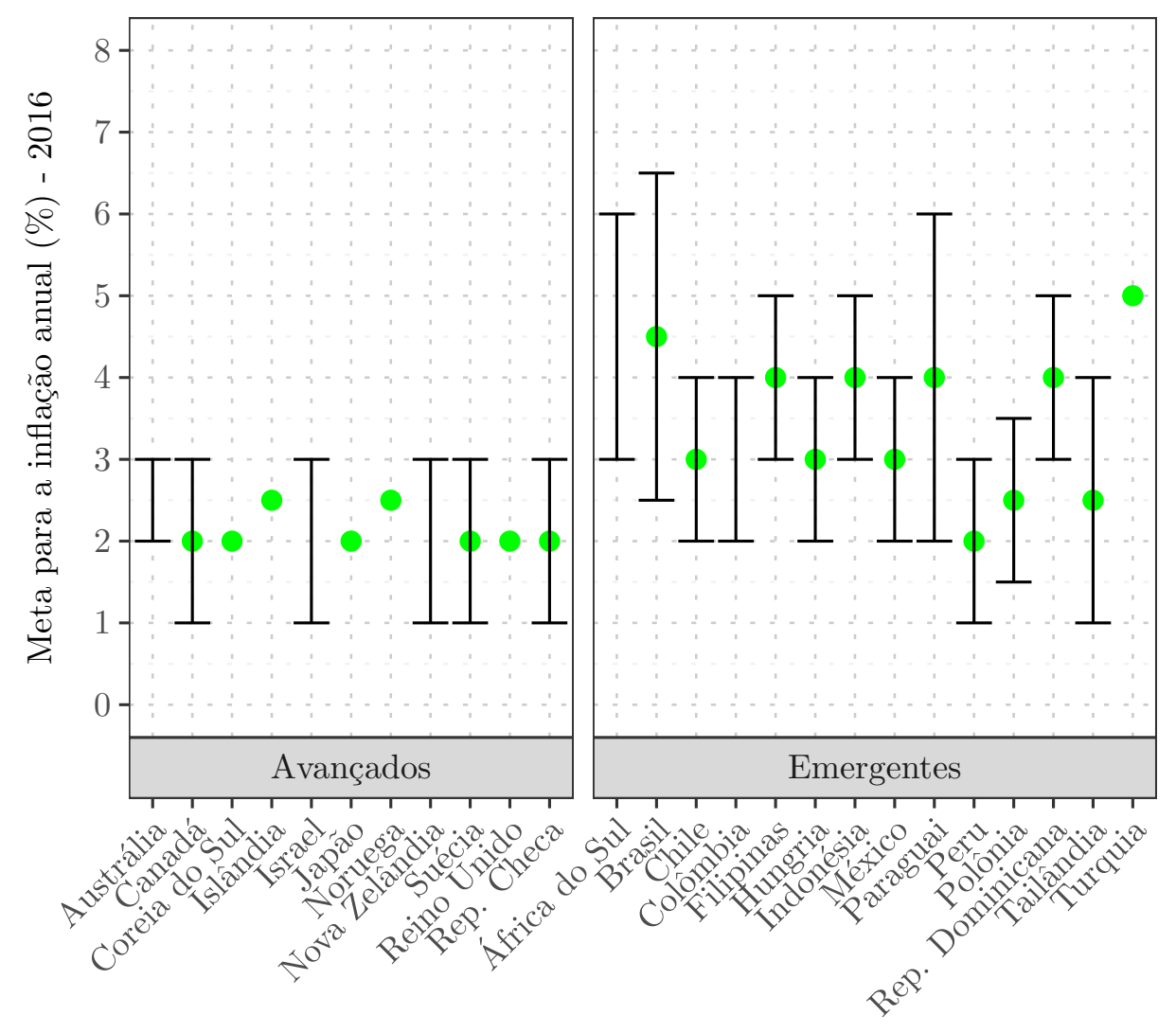

Fonte: Dados extraídos do site do banco central de cada país.

De acordo com Brito and Bystedt (2010), a ausência de maturidade institucional e de consistência dos fundamentos macroeconômicos de economias emergentes que optam pelo regime de metas para a inflação podem prejudicar a credibilidade da política monetária. ${ }^{1}$ Instituições fiscais e financeiras pouco desenvolvidas aparecem como as principais características comuns

\footnotetext{
${ }^{1}$ Ver também Bernanke and Woodford (2005), Caballero and Krishnamurthy (2005), Mishkin (2000, 2004) e Sims (2005).
} 
aos países emergentes listadas por Calvo and Mishkin (2003). Nesta direção, Gonçalves and Carvalho (2008) buscam responder quais os fatores por trás da decisão do policymaker em optar pelo regime de metas para a inflação. Para os autores, países com maior inflação no passado, níveis de dívida mais baixos e ausência de uma âncora cambial, são mais propensos a adotar esta estratégia de política monetária. Samaryna and Haan (2011) ao darem mais profundidade nos estudos desta área, somaram às variáveis macroeconômicas e fiscais, as financeiras e institucionais. Os resultados sugerem diferentes pré-condições para o regime de metas entre países da OECD e não-OECD.

Diferentemente destes últimos trabalhos que analisam as pré-condições ou a capacidade que um país tem em alcançar a meta para a inflação, Araujo et al. (2016) discutem as condições para que uma meta baixa seja preferível a uma meta alta. Em outras palavras, os autores questionam a meta em si e argumentam que países que não possuem fortes fundamentos macroeconômicos poderiam optar por uma estratégia gradualista de política monetária na qual o declínio da meta para a inflação está associado à uma melhora dos fundamentos macroeconômicos do país em questão.

A partir dos anos 90, um número crescente de países implementou o regime de metas. Muitos deles, já com fortes fundamentos macroeconômicos, optaram por metas para a inflação cada vez mais ambiciosas, conforme ilustrado na Figura $1.2 .^{2}$ Isto pode ser explicado por meio de reformas no âmbito macroeconômico, microeconômico e institucional que são, geralmente, implementadas de forma gradual. Assim, uma meta para a inflação menos ambiciosa pode gerar maior credibilidade e, consequentemente, uma melhor coordenação das expectativas de inflação. Araujo et al. (2016), então, mostram que metas ambiciosas podem indicar um compromisso com inflação baixa somente se forem críveis, mas, no caso oposto, geram desconfiança de que a meta não seja alcançada. Desta forma, há um trade-off entre metas baixas e críveis para a inflação.

Usando dados de 25 países avançados e emergentes aderentes do regime de metas para a inflação, este trabalho tem por objetivo investigar empiricamente as condições discutidas por Araujo et al. (2016), ou dito de outra forma, se os fundamentos macroeconômicos determinam a meta para a inflação. Se as metas dependem dos fundamentos, então existe uma evidência de que os países adotam uma estratégia gradualista. Nesta perspectiva, bons fundamentos encorajam a adoção de metas ambiciosas, mas países em situações frágeis levam mais tempo para estipularem uma meta para a inflação baixa. Portanto, diferentemente da literatura empírica que investiga a eficácia do sistema de metas, busca-se aqui investigar como os países definem a meta em si.

Com intuito de controlar a heterogeneidade entre os países da amostra, os dados em painel

\footnotetext{
${ }^{2}$ A América Latina, por exemplo, foi a região com as maiores taxas de inflação mundial até o início da década de 90 .
} 
Figura 1.2: Histórico das metas para a inflação para os países da América Latina.

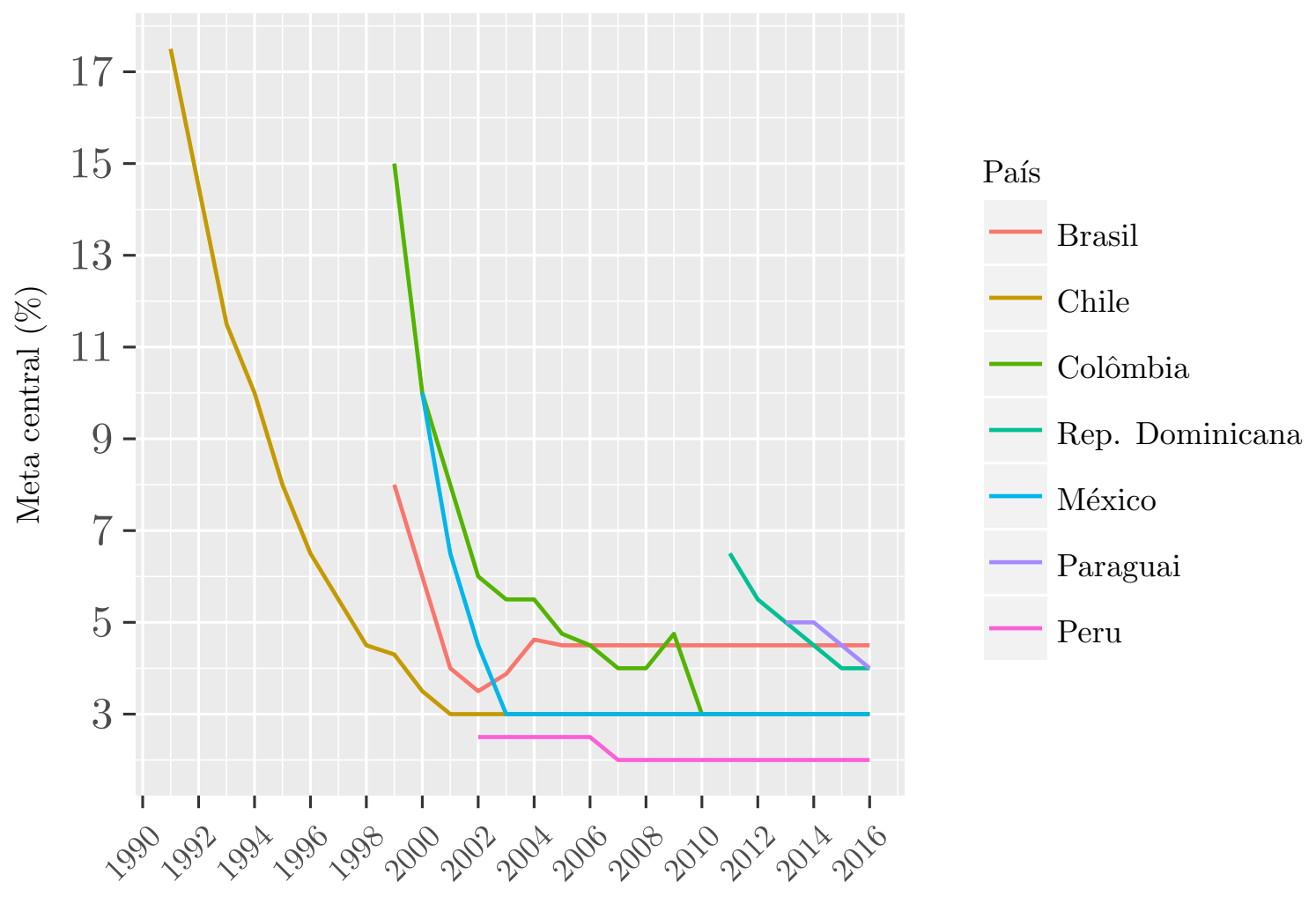

Fonte: Dados extraídos do site do banco central de cada país.

surgem como estratégia empírica para estimar os determinantes das metas para a inflação. As variáveis explicativas escolhidas como possíveis determinantes servem como medida dos fundamentos macroeconômicos tais como inflação, nível de atividade econômica e situação fiscal. Os estimadores usados neste trabalho são: Mínimos Quadrados Ordinários, Efeito Fixo e Efeito Aleatório.

Antecipando os resultados, encontra-se que coeficiente da inflação apresenta sinal positivo, indicando que um nível mais alto de inflação está associado a uma meta elevada. Já os coeficientes do estoque e do fluxo da dívida bruta/PIB, com algumas diferenças entre as suas significâncias, apresentam sinal positivo e negativo, respectivamente, sendo que o último contraria a teoria econômica. O crescimento do PIB apresenta sinal negativo, conforme esperado. As dummies incluídas no modelo para países emergentes e para bandas de tolerância indicam que, em relação a primeira, bons fundamentos, características comuns aos países avançados, estão relacionados a uma meta baixa. A segunda aponta que, se o país anuncia bandas, o banqueiro central pode estipular uma meta baixa para a inflação, explorando, assim, o trade-off entre flexibilidade e credibilidade proposto por Lohman (1992).

Este trabalho é composto de mais quatro capítulos além desta introdução. No segundo 
capítulo é feita uma revisão de literatura em torno das pré-condições ditas anteriormente. O terceiro capítulo discute os dados e metodologia utilizada. Os resultados obtidos para o modelo empírico se encontram no quarto capítulo. Finalmente o quinto, e último capítulo, apresenta a conclusão.

\section{Capítulo 2}

\section{Revisão de Literatura}

Em meados dos anos 70, muitos países avançados, inclusive os EUA, experimentaram a estagflação, situação na qual altas inflacionárias são acompanhadas por altas taxas de desemprego. Após alguns anos de pesquisa para entender o que estava por trás deste fenômeno, os macroeconomistas chegaram a duas explicações: a primeira estava relacionada aos efeitos dos choques adversos de oferta tanto sobre os preços quanto sobre o produto; ${ }^{1}$ a segunda, por sua vez, baseava-se na discricionariedade de políticas keynesianas. ${ }^{2}$ Desta última, surgiu a hipótese das expectativas racionais formulada inicialmente por John Muth na década de 60, mas que teve notoriedade nos trabalhos de Lucas e Sargent na década de 70, que implicavam que políticas contra-cíclicas, quando antecipadas pelos agentes econômicos, não tinham efeito algum sobre variáveis reais. Posteriormente, a hipótese das expectativas racionais foi incorporada à formulação de políticas econômicas em que se questionava qual seria a melhor forma de conduzir a política monetária. Em outras palavras, questionava-se em que medida os bancos centrais deveriam seguir regras preestabelecidas, dado que uma regra muito rígida poderia comprometer a estabilização do produto em um ambiente macroeconomicamente volátil, porém evitaria pressões inflacionárias indevidas e suas consequências para a atividade econômica. Para tanto, um mecanismo que garantisse o cumprimento de tal regra deveria existir. Enquanto que na discrição, qualquer comprometimento da autoridade monetária estaria sujeito ao problema de inconsistência intertemporal que acionaria o viés inflacionário (Kydland and Prescott (1977)).

\footnotetext{
${ }^{1}$ Ver página 144 de Blachard (2007).

${ }^{2}$ Ver Lucas and Sargent (1979).
} 


\subsection{Viés Inflacionário}

O viés inflacionário manifesta-se quando, por exemplo, questões relacionadas à atividade econômica ou ao tamanho do déficit fiscal começam a ganhar relevância nas decisões de política monetária, incentivando, assim, o banco central a praticar políticas inflacionistas. Como resultado de expectativas racionais, os agentes econômicos antecipam uma taxa de inflação acima daquela anunciada (Cukierman and Gerlach (2003)).

Isto pode ser verificado por meio de uma função de perda social a cada período t como

$$
L_{t}=\frac{1}{2}\left[\left(\pi_{t}-\pi^{a}\right)^{2}+\gamma\left(h_{t}\right)^{2}\right]
$$

em que o banqueiro central busca minimizar o desvio entre inflação $\left(\pi_{t}\right)$ no período $t$ e meta anunciada $\left(\pi^{a}\right)$, porém com alguma preocupação medida por $\gamma \geq 0$ quanto à estabilização da economia real dada pelo hiato do produto $\left(h_{t}\right){ }^{3}$ As restrições para esta minimização são dadas pela estrutura da economia, representadas em geral por uma Curva IS que relaciona o hiato do produto inversamente à taxa de juros real e por uma Curva de Phillips que relaciona inflação diretamente ao hiato do produto. ${ }^{4}$

Desta forma, em busca de mitigar o viés inflacionário da política monetária, a literatura tem proposto as seguintes soluções:

1. Kydland and Prescott (1977) sugerem que o policymaker deveria seguir regras em vez de políticas discricionárias, havendo, claro, um mecanismo para garantir o cumprimento da regra.

2. Barro and Gordon (1983), por sua vez, ressaltam a importância da reputação e dos ganhos de credibilidade que advém de um compromisso crível com inflação baixa. Desta maneira, ganhos de reputação podem impedir surtos inflacionários derivados do excesso de discricionariedade.

3. Rogoff (1985) sugere a indicacão de um banqueiro central independente e conservador, isto é, mais avesso à inflação do que a média da sociedade de maneira que este agente tenha pouco estímulo, por exemplo, para explorar o trade-off entre inflação e produto. Lohman (1992), por seu turno, propõe que a política monetária seja delegada a um banqueiro central conservador, porém parcialmente independente. Este agente deve estabelecer uma certa taxa de inflação em circunstâncias normais e implementar uma cláusula de escape flexível em situações extremas.

\footnotetext{
${ }^{3}$ Ver Svensson (1999).

${ }^{4}$ Ver Clarida et al. (1999).
} 
4. Walsh (1995), munido pela teoria de contratos, propôs que o problema do viés inflacionário pode ser mitigado por uma estrutura de contratos ótimos que podem punir o banco central quando a inflação se desviar daquela socialmente desejada. Assim, o governo (principal) e o banco central (agente) estabelecem um contrato no qual o agente está sujeito à um conjunto de punições que o induzem ao comprometimento com inflação baixa. O banco central, então, internaliza o efeito de suas decisões e, por isso, pondera antes de acionar o viés inflacionário. As metas para a inflação, por sua vez, são analisadas como um contrato ótimo no modelo de Svensson (1997), no qual a sociedade (o principal) delega a política monetária para o banco central (o agente). O conservadorismo deste agente pode ser medido pela meta anunciada, a qual sinaliza que a taxa de inflação por ele desejada é menor do que àquela que a sociedade deseja.

Enquanto que os modelos de Barro e Gordon e de Rogoff, bem como o de Walsh, tratam de desenhos institucionais de bancos centrais, o sistema de metas inflacionárias foi inspirado originalmente na formulação do problema da inconsistência intertemporal por Kydland e Prescott em 1977. Mais ainda, segundo Andersson and Jonung (2017), a raiz teórica deste regime remonta à teoria de Knut Wicksell em 1898, que relaciona juros e preços. Nela, um banco central pode afetar a taxa de inflação pelo uso de sua taxa de juros. Desta forma, o objetivo de política monetária deveria ser a estabilidade do nível de preços.

\subsection{Caracterização do Regime de Metas para a Inflação}

Para Bernanke and Mishkin (1997), o regime de metas para a inflação pode ser classificado como uma estratégia (framework) de política monetária que melhora a comunicação, transparência, coerência da política e a accountability do banco central para atingir os objetivos de política monetária. Este regime, portanto, caracterizado como uma regra mais flexível, serve tanto para ancorar as expectativas dos agentes econômicos como para conceder a possibilidade ao banco central de acomodar ou reagir a choques exógenos inesperados. Desta maneira, as metas para a inflação devem englobar os seguintes elementos (Mishkin (2000)):

i anúncio público de uma meta numérica de médio prazo para a inflação;

ii comprometimento institucional com a estabilidade de preços como objetivo principal da política monetária, ao qual os outros objetivos estão subordinados; 
iii uma estratégia inclusiva de informações em que muitas variáveis e não somente os agregados monetários ou a taxa de câmbio é utilizado nas decisões relacionadas aos instrumentos de política;

iv maior transparência da estratégia de política monetária por meio da comunicação com o público e mercados sobre os planos, objetivos e decisões das autoridades monetárias;

v aumento da accountability dos bancos centrais para alcance dos objetivos de inflação.

\subsubsection{Pré-condições para a adoção do regime de metas inflacionárias}

Uma objeção às metas para a inflação, conforme FMI (2005), é o seu alto custo em termos de requisitos institucionais e técnicos. Assim, a capacidade que um país tem em alcançar a meta depende do compromisso por parte do banco central com taxas de inflação baixas e estáveis logo nas fases iniciais de implementação do regime. Para Jonas and Mishkin (2003) a eficácia do regime de metas para a inflação tem importantes pré-condições que precisam ser cumpridas pela autoridade monetária para o controle inflacionário. São elas:

- posição fiscal forte;

- sistema financeiro bem desenvolvido;

- entendimento dos mecanismos de transmissão de política monetária;

- capacidade razoavelmente bem desenvolvida de prever a inflação ;

- política monetária transparente e responsável;

- independência do banco central e um mandato orientado para a estabilidade de preços;

- Nenhuma outra âncora nominal.

Uma política fiscal equilibrada e disciplinada é aquela que apresenta uma situação fiscal sob controle para evitar contágio sobre a política monetária, isto é, que apresente ausência de dominância fiscal. O debate acerca da interação entre política fiscal e monetária explorado por Sargent and Wallace (1987) é importante para o sucesso do regime de metas, uma vez que para esses autores, há dois possíveis cenários de interação entre ambas as políticas econômicas que podem resultar em uma dominância monetária ou em uma dominância fiscal. Na primeira, a 
autoridade fiscal está comprometida com a geração de superávits primários necessários para estabilizar a razão dívida/PIB. Desta maneira, a autoridade monetária é independente da autoridade fiscal, visto que não sofre pressões para financiar o déficit fiscal via expansão da base monetária. Já na segunda, a inflação de longo prazo não é aquela almejada pela autoridade monetária, uma vez que o banco central precisa gerar receitas de senhoriagem necessárias para estabilizar a razão dívida/PIB. Desta maneira, perde-se o controle da inflação por causa de desequílibrios fiscais.

À vista disto, Kumhof et al. (2010) concluem que a disciplina fiscal deve ser estabelecida previamente ao comprometimento com o regime de metas inflacionárias, pois caso contrário o banco central não pode definir a taxa de juros - principal instrumento do regime de metas para minimizar o desvio entre a expectativa de inflação e a meta anunciada - sem avaliar os efeitos sobre a razão dívida/PIB. Trata-se, então, da interação entre a solvência fiscal e os limites para combater a inflação. Tais limites são enfrentados pelo banco central se a taxa de juros for elevada para reduzir a aceleração de preços, ao passo que, a restrição orçamentária do governo traz incentivos para evitar esta elevação (Araujo et al. (2016)).

Para Samaryna and Haan (2011), instituições financeiras fracas e instáveis podem criar circunstâncias sob as quais o banco central não pode aumentar as taxas de juros para sustentar a meta para a inflação, uma vez que isto pode causar o colapso do frágil setor bancário e, posteriormente, levar a uma crise financeira. Por esta razão, é imprescindível para o funcionamento adequado do regime de metas, instituições financeiras fortes e bem desenvolvidas a fim de absorver choques financeiros de curto prazo, minimizando seus impactos sobre a economia real.

Conforme Hammond (2012), o regime de metas requer que o banco central tenha elevada capacidade técnica para modelar a economia e para entender os mecanismos de transmissão da política monetária. Os modelos estocásticos e de equilíbrio geral (DGSE) são usados pela maioria dos bancos centrais para, por exemplo, estimação, previsão, comparação de modelos, identificação de choques e análise da política monetária.

Além disto, uma capacidade técnica em termos de previsão bem desenvolvida é crucial para o sucesso do regime de metas. Isto porque, uma meta numérica explícita para a taxa de inflação é uma característica do regime. De acordo com Beechey and Osterholmb (2010), a meta atua como um ponto focal tanto para os esforços do banco central para coordenar as expectativas de inflação dos agentes quanto para suas próprias decisões políticas. Quando o compromisso do banco central de atingir a meta não é apenas forte, mas também percebido como credível pelos agentes, a meta para a inflação provavelmente constitui-se como um guia adequado para 
a inflação futura. Assim, um instrumento razoável para previsão de inflação é necessário na definição de metas críveis que forneçam informações prévias úteis para o nível de inflação.

A transparência (comunicação) e a accountability do banco central por meio de relatórios de inflação, cartas abertas e publicações no geral, que analisam as condições da economia, bem como possíveis riscos, sinalizam ao público as decisões de política monetária, o que aumenta a consistência da política de metas (Hammond (2012)).

Embora nem todos os bancos centrais tenham ganhado total liberdade para estabelecer uma política monetária de metas inflacionárias, a maioria ganhou independência de instrumentos, ou seja, liberdade para perseguir a meta sem interferência de natureza política. Há um consenso entre os economistas de que os bancos centrais devem ter indepêndencia de instrumentos, porém, também há um consenso de que os bancos centrais não devem ter independência de objetivos, ou seja, independência para definir objetivos de meta e de política monetária (Mishkin (2004)).

Por fim, no regime de metas, as decisões do banco central se baseiam no controle de apenas um instrumento, a taxa de juros. Desta forma, não pode existir mais de uma âncora nominal.

O banco central do Brasil resume bem estas pré-condições: ${ }^{5}$

Em um regime de metas para a inflação, é necessário que haja autonomia operacional do banco central, de maneira que possa gerir a política monetária no sentido do cumprimento das metas. Além disto, é necessário que a situação fiscal esteja sob controle e que o sistema financeiro nacional esteja estável, de modo a não comprometer a perseguição da meta. Por outro lado, as metas para a inflação devem ser críveis, ou seja, devem ter valor alcançável. Por fim, é preciso que o banco central disponha de conhecimento sobre o funcionamento da economia, em particular dos mecanismos de transmissão da política monetária e sua quantificação por meio de modelos macroeconômicos.

\subsubsection{Como a meta para a inflação é defi- nida?}

De acordo com o FMI (2005), a ausência das pré-condições listadas acima tornam a política de metas insustentável para muitos países emergentes que optam pelo regime, em certo grau, para países avançados também. Isto porque, em geral, países emergentes apresentam fundamentos

\footnotetext{
${ }^{5}$ Ver página 6 do documento disponível no site: https://www.bcb.gov.br/Pec/Metas/10_anos_metas_ inflacao_completo.pdf.
} 
piores quando comparados aos países avançados. Neste sentido, Araujo et al. (2016) analisam quais as condições para que uma meta baixa para a inflação seja preferida a uma meta alta.

Para isto, os autores consideram um jogo de três estágios tendo como jogadores o banco central e os agentes. No primeiro estágio, o banco central anuncia a meta para a inflação, $\pi^{a}$. Dada a meta anunciada, no segundo estágio os agentes formam suas expectativas, $\pi^{e}$, de acordo com o conjunto informacional disponível. No último estágio, o banco central escolhe, $\pi$, a taxa de inflação efetiva pela minimização de uma função perda de bem-estar social. Esta função é composta por dois fatores, $L\left(\pi, \pi^{e}\right)$, que descreve suas preferências, mais um custo, $k \in \mathbb{R}$, associado ao desvio da meta para a inflação anunciada, dada por

$$
L\left(\pi, \pi^{e}\right)+I_{k, \pi}
$$

em que

$$
I_{k, \pi}=\left\{\begin{array}{lll}
0 & \text { se } & \pi=\pi^{a} \\
k & \text { se } & \pi \neq \pi^{a}
\end{array}\right.
$$

Os autores, então, definem metas altas como aquelas praticadas por uma política monetária discricionária, $\pi_{D}$, e no caso oposto, para metas baixas, como aquelas praticadas sob total comprometimento, $\pi_{R}$.

Os resultados são apresentados em duas estruturas distintas: sob informação completa acerca da estrutura de incentivos do banco central para o cumprimento da meta, a definição de uma meta alta sinaliza aos agentes um baixo comprometimento com este objetivo, o qual é interpretado pelos eles como um termômetro do atual estado da economia e, assim, um equilíbrio único se verifica em que $\pi^{e}=\pi_{D}$. Entretanto, o mesmo não ocorre para a definição de uma meta mais ambiciosa, o que leva a múltiplos equilíbrios. ${ }^{6}$ Sob global games, em que os agentes têm informação imperfeita acerca da estrutura de incentivos do banco central, os resultados anteriores permanecem: uma meta ambiciosa requer fortes fundamentos macroeconômicos para assegurar um equilíbrio único.

Desta forma, Araujo et al. (2016) concluem que metas baixas são inatingíveis, levando ao trade-off entre metas baixas e críves para a inflação. A Figura 2.1 mostra este resultado. Um alto comprometimento, $k$, garante que $\pi^{e}=\pi^{a}$. Ademais, quando $k \leq 0, \pi^{e}=\pi_{D}$ também é um equilíbrio único. Para algum $k$ entre estes extremos, os agentes podem discordar sobre o próximo $\pi$. Assim, como $\pi^{a}$ move de $\pi_{R}$ para $\pi_{D}$, a região de múltiplos equilíbrios (E.M.) entre as duas curvas diminui. Além disto, países com fundamentos fracos precisam impor metas críveis para gerar maior credibilidade e, consequentemente, uma melhor coordenação das expectativas

\footnotetext{
${ }^{6}$ Mais detalhes sobre múltiplos equilíbrios, Morris and Shin (2001), Angeletos and Werning (2006).
} 
de inflação.

Figura 2.1: Metas altas e baixas para a inflação.

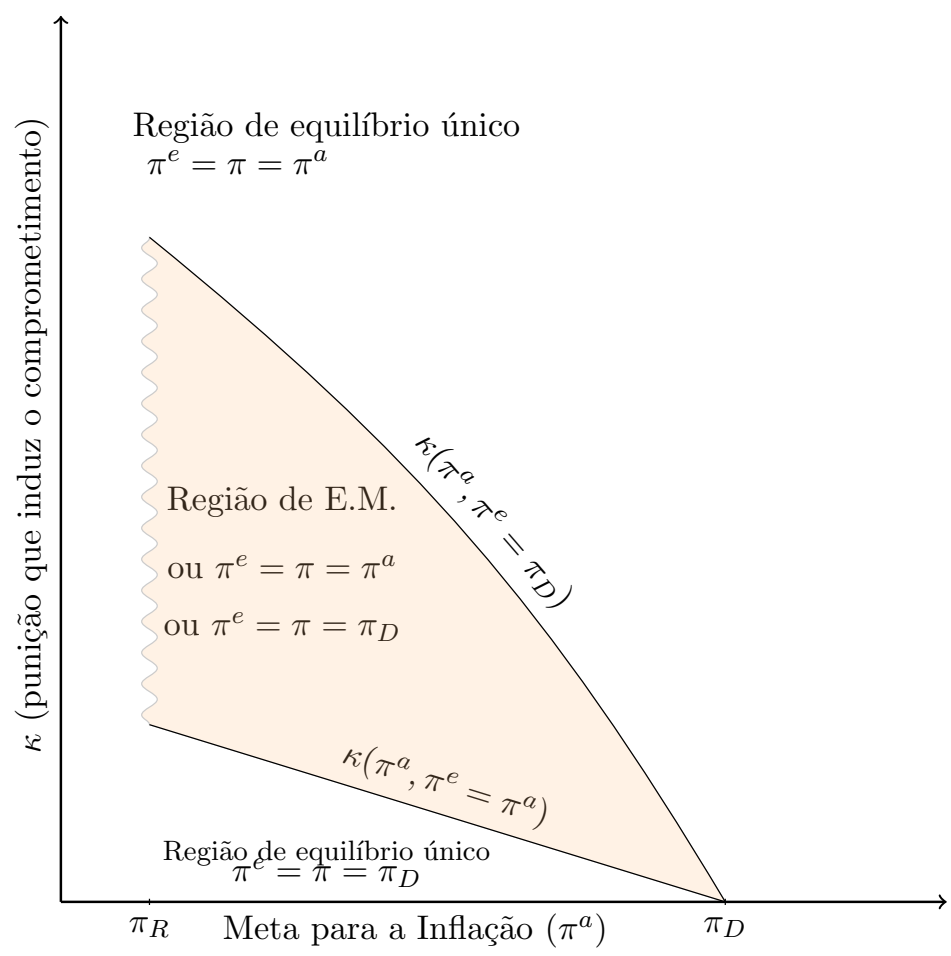

À luz deste estudo, os próximos capítulos investigam empiricamente se as metas para a inflação dependem de fundamentos macroeconômicos. Se esta relação for verificada, então existe uma evidência de que países adotam uma estratégia gradualista de política monetária, na qual metas cada vez mais ambiciosas estão relacionadas com fundamentos macroeconômicos cada vez mais fortes.

\section{Capítulo 3}

\section{Dados e Metodologia Empírica}

A Tabela 3.1 apresenta os 25 países da amostra utilizada que são adeptos do regime de metas para a inflação - avançados e emergentes - segundo a classificacão do FMI.

O objetivo deste trabalho é estimar os determinantes das metas para a inflação. Em alguns 
países, entretanto, a meta é constante ao longo do tempo. Estes países não alteraram suas metas iniciais para a inflação, tais como: Austrália, Canadá, Islândia, Japão, Noruega, África do Sul, Suécia e Reino Unido. Isto pode ser verificado na coluna 7 da Tabela 3.1. Desta forma, opta-se por três abordagens distintas:

1. Utiliza-se os dados em painel desbalanceado apenas para os países que têm variação na meta para a inflação. Para isto, considera-se aqueles cujo o desvio padrão da meta, desde o ano de adoção do regime, é maior que 0. Ao todo são 17 países. Os dados têm frequência anual com início no ano de adoção da meta - ver coluna 2 da Tabela 3.1 - até 2016, exceto para Brasil, Chile e Israel, que por uma questão de escassez de dados, têm início em 2002, 1992 e 1993, respectivamente.

2. Com o intuito de atenuar o desbalanceamento do painel, utiliza-se a mesma amostra de países cujo o desvio padrão da meta, desde o ano de 2000, é maior que 0. Os dados, novamente, têm frequência anual com início no ano de 2000 até 2016. Ainda por conta da escassez de dados, as séries para o Brasil têm início em 2002.

3. Por fim, considerando os 25 países da amostra, inclusive aqueles que não têm variação na meta, estima-se o modelo para cada cross-section a partir de 2000 até 2016.

O modelo empírico, para dados em painel, tem a seguinte forma geral:

$$
\pi_{i, t}^{a}=\boldsymbol{\beta} \mathbf{X}_{i, t-1}+\alpha_{i}+\epsilon_{i, t}
$$

em que $\pi_{i, t}^{a}$ é a meta para a inflação anunciada no ano $t$ e no país $i . \mathbf{X}_{i, t-1}$ é o vetor de variáveis explicativas do país $i$ e no ano t-1. Finalmente, $\boldsymbol{\beta}$ é o vetor de parâmetros a ser estimado, $\alpha_{i}$ captura o efeito fixo, aquele que controla as diferenças entre os países e que permanecem constantes ao longo do tempo e $\epsilon_{i, t}$ é um resíduo.

Muitos países anunciam suas metas para a inflação com um ano de antecedência, pelo menos. Por esta razão, todas as variáveis explicativas estão defasadas em um ano, além, claro, da defasagem capturar a estratégia de política monetária que, por sua vez, necessita de tempo para surtir efeito. Mais que isto, o uso da defasagem também elimina suspeitas de endogeneidade nos regressores.

As variáveis explicativas, $\mathbf{X}_{i, t-1}$, selecionadas para o modelo medem os fundamentos macroeconômicos e são baseadas nos estudos de Gonçalves and Carvalho (2008) e de Samaryna and Haan (2011), os quais analisam os determinantes da adoção do regime de metas para a inflação. Adicionalmente, variáveis dummies também são incluídas como proxy, e para indicar a pre- 
Tabela 3.1: Dados para os 25 países utilizados.

\begin{tabular}{|c|c|c|c|c|c|c|c|c|}
\hline \multicolumn{9}{|c|}{ Avançados } \\
\hline & $\begin{array}{l}\text { País } \\
(1)\end{array}$ & $\begin{array}{c}\text { Ano de Adoção } \\
(2)\end{array}$ & $\begin{array}{c}\text { Meta Inicial } \\
(3)\end{array}$ & $\begin{array}{l}\text { Meta Final } \\
\text { (4) }\end{array}$ & $\begin{array}{l}\text { ME Adoção } \\
(5)\end{array}$ & $\begin{array}{l}\text { ME } 2000 \\
(6)\end{array}$ & $\begin{array}{c}\text { DP Adoção } \\
(7)\end{array}$ & $\begin{array}{c}\text { DP } 2000 \\
(8)\end{array}$ \\
\hline 1 & Austrália & 1993 & 2.50 & 2.50 & 2.50 & 2.50 & 0.00 & 0.00 \\
\hline 2 & Canadá & 1991 & 2.00 & 2.00 & 2.00 & 2.00 & 0.00 & 0.00 \\
\hline 3 & Coreia do Sul & 1998 & 9.00 & 2.00 & 3.24 & 2.91 & 1.42 & 0.26 \\
\hline 4 & Islândia & 2001 & 2.50 & 2.50 & 2.50 & 2.50 & 0.00 & 0.00 \\
\hline 5 & Israel & 1992 & 14.50 & 2.00 & 4.36 & 2.18 & 3.62 & 0.43 \\
\hline 6 & Japão & 2013 & 2.00 & 2.00 & 2.00 & 2.00 & 0.00 & 0.00 \\
\hline 7 & Noruega & 2001 & 2.50 & 2.50 & 2.50 & 2.50 & 0.00 & 0.00 \\
\hline 8 & Nova Zelândia & 1990 & 1.00 & 2.00 & 1.57 & 1.82 & 0.40 & 0.25 \\
\hline 9 & Suécia & 1996 & 2.00 & 2.00 & 2.00 & 2.00 & 0.00 & 0.00 \\
\hline 10 & Reino Unido & 1992 & 2.00 & 2.00 & 2.00 & 2.00 & 0.00 & 0.00 \\
\hline 11 & Rep. Checa & 1998 & 6.00 & 2.00 & 3.05 & 2.79 & 1.10 & 0.79 \\
\hline \multicolumn{9}{|c|}{ Emergentes } \\
\hline & $\begin{array}{l}\text { País } \\
(1)\end{array}$ & $\begin{array}{l}\text { Ano de Adoção } \\
\text { (2) }\end{array}$ & $\begin{array}{l}\text { Meta Inicial } \\
(3)\end{array}$ & $\begin{array}{c}\text { Meta Final } \\
(4)\end{array}$ & $\begin{array}{l}\text { ME Adoção } \\
(5)\end{array}$ & $\begin{array}{c}\text { ME } 2000 \\
(6)\end{array}$ & $\begin{array}{c}\text { DP Adoção } \\
(7)\end{array}$ & $\begin{array}{c}\text { DP } 2000 \\
(8)\end{array}$ \\
\hline 1 & Africa do Sul & 2002 & 4.50 & 4.50 & 4.50 & 4.50 & 0.00 & 0.00 \\
\hline 2 & Brasil & 1999 & 8.00 & 4.50 & 4.67 & 4.47 & 0.96 & 0.49 \\
\hline 3 & Chile & 1991 & 17.50 & 3.00 & 5.15 & 3.03 & 3.96 & 0.12 \\
\hline 4 & Colômbia & 1999 & 15.00 & 3.00 & 5.17 & 4.59 & 3.12 & 1.98 \\
\hline 5 & Filipinas & 2002 & 5.50 & 4.00 & 4.43 & 4.43 & 0.42 & 0.42 \\
\hline 6 & Hungria & 2001 & 7.00 & 3.00 & 3.50 & 3.50 & 1.03 & 1.03 \\
\hline 7 & Indonésia & 2005 & 6.00 & 4.00 & 5.08 & 5.08 & 1.12 & 1.12 \\
\hline 8 & México & 2000 & 10.00 & 3.00 & 3.71 & 3.71 & 1.85 & 1.85 \\
\hline 9 & Paraguai & 2013 & 5.00 & 4.00 & 4.63 & 4.63 & 0.48 & 0.48 \\
\hline 10 & Peru & 2002 & 2.50 & 2.00 & 2.17 & 2.17 & 0.24 & 0.24 \\
\hline 11 & Polônia & 1998 & 9.50 & 2.50 & 3.76 & 3.22 & 2.13 & 1.42 \\
\hline 12 & Rep. Dominicana & 2011 & 6.50 & 4.00 & 4.92 & 4.92 & 0.97 & 0.97 \\
\hline 13 & Tailândia & 2000 & 1.75 & 2.50 & 1.84 & 1.84 & 0.25 & 0.25 \\
\hline 14 & Turquia & 2006 & 5.00 & 5.00 & 5.23 & 5.23 & 1.01 & 1.01 \\
\hline \multicolumn{9}{|c|}{$\begin{array}{l}\text { Nota: A coluna } 2 \text { refere-se ao ano em que o regime de metas foi adotado. Na coluna } 3 \text { consta a meta para a inflação } \\
\text { definida para o ano de adoção do regime, enquanto que na coluna } 4 \text { consta a meta para a inflação no ano de } 2016 \text {. A } \\
\text { coluna } 5 \text { mostra a média da meta desde o ano de adoção até } 2016 \text {, enquanto que na coluna } 6 \text { mostra a média da meta a } \\
\text { partir de } 2000 \text { até } 2016 \text {. A coluna } 7 \text { apresenta o desvio padrão da meta desde o ano de adoção até } 2016 \text {, enquanto que a } \\
\text { coluna } 8 \text { mostra a desvio padrão da meta a partir de } 2000 \text { até } 2016 \text {. Conforme Figura } 1.1 \text {, muitos países adotam bandas } \\
\text { de tolerância. No entanto, como o objetivo deste trabalho é estimar a meta em si, a tabela acima apresenta somente a } \\
\text { meta pontual. }\end{array}$} \\
\hline
\end{tabular}

sença ou ausência de determinada característica. As séries foram obtidas pelo World Economic Outlook (WEO) de 2017 do Fundo Monetário Internacional (descritas na Tabela 3.2). Seguem:

Tabela 3.2: Descrição dos dados.

\begin{tabular}{lcc}
\hline Série & Variável & Unidade de Medida \\
\hline CPI & Inflação & $(\%)$ ao ano, variação acumulada \\
Dívida bruta/PIB & DBGG/PIB & $(\%)$ PIB ao ano, acumulado \\
Dívida bruta/PIB & $\Delta($ DBGG/PIB $)$ & $($ p.p. $) \mathrm{DBGG}_{t} / \mathrm{PIB}_{t}-\mathrm{DBGG}_{t-1} / \mathrm{PIB}_{t-1}$ \\
PIB real & $\Delta$ LPIB & $(\%)$ ao ano, $\ln \left(\mathrm{PIB}_{t}\right)-\ln \left(\mathrm{PIB}_{t-1}\right)$ \\
\hline Nota: Taxa de crescimento do PIB real $(\Delta \mathrm{LPIB}) ;$ estoque da dívida \\
bruta/PIB (DBGG/PIB), e fluxo da dívida bruta/PIB $(\Delta(\mathrm{DBGG} / \mathrm{PIB}))$.
\end{tabular}

\section{- Inflação}

Há diversos estudos a respeito da taxa de inflação ideal de uma economia, isto é, aquela que maximiza o bem-estar econômico. Estabelecer uma meta apropriada para a inflação requer a compreensão sobre como o processo inflacionário afeta a estabilidade da economia, bem como o bem-estar (Billy and Kahn (2008)). Para Kim and Kim (2009), por exemplo: 
In setting the inflation target itself at the range of $3.0 \%+/-0.5$ p.p., the Bank aims to reflect the appropriate rate of inflation consistent with Korean economic fundamentals and to allow itself flexibility in conducting monetary policy to deal with short-term economic fluctuations.

Desta forma, a hipótese é que uma inflação mais baixa, reflexo da consistência dos fundamentos de políticas econômicas, está associada a uma meta para a inflação mais ambiciosa.

\section{- Dívida Bruta do Governo Geral (DBGG)/PIB}

A DBGG é uma variável que mede a solvência fiscal de um determinado país. Conforme exposto ao longo da revisão de literatura deste trabalho, a sustentabilidade fiscal é frequentemente considerada como pré-condição para o regime de metas. Estudos recentes, indicam que, mais importante que o estoque da dívida, é a reação da política fiscal por meio de superávits primários a variações na razão dívida/PIB (Bohn (2007)). Desta forma, utilizase como variável explicativa não apenas o estoque da dívida bruta/PIB, como também o fluxo.

A hipótese é que uma trajetória (ou nível) da dívida bruta/PIB estável ou decrescente (constante ou baixo) pode diminuir a meta para a inflação. Isto porque uma política fiscal imprevisível pode forçar o banco central a financiar déficits fiscais ao custo de uma inflação mais alta. Assim, uma política fiscal equilibrada e disciplinada é essencial para o controle inflacionário e, portanto, para o declínio das metas.

\section{- Crescimento do PIB real}

É razoável pensar que o objetivo de políticas macroeconômicas é um crescimento elevado e sustentável conjuntamente com uma inflação baixa. Desta forma, a hipótese é que, no longo prazo, haja uma relação negativa entre crescimento econômico e metas para a inflação, visto que é mais factível propor uma mudança institucional, como a redução de metas, quando a economia está saudável.

\section{- Dummy para Emergentes}

Países emergentes, geralmente, têm fundamentos piores em relação aos países avançados, levando mais tempo para estipularem uma meta baixa para a inflação. Desta forma, esta variável entra no modelo como proxy para a qualidade dos fundamentos macroeconômicos. Assim, a hipótese é que se o país for emergente, então a meta para a inflação é alta. A dummy possui valor igual 1 para países emergentes, e 0 caso contrário. 


\section{- Dummy para Bandas de Tolerância}

Bandas são definidas em ambientes macroeconomicamente voláteis, permitindo flexibilidade para a política monetária na presença de fatores conjunturais de curto prazo. A hipótese é que se o país anuncia bandas, mais risco pode-se assumir e, portanto, menor é a meta para a inflação, uma vez que o banqueiro central não perde credibilidade por trafegar entre o limite inferior e superior da banda, podendo, assim, estipular uma meta baixa, sabendo que a economia do país em questão está sujeita a incertezas. A dummy possui valor igual 1 para países que adotam bandas, e 0 caso contrário.

Tabela 3.3: Hipóteses a serem testadas.

\begin{tabular}{l|cc}
\hline \hline Hipótese & Variável & $\begin{array}{c}\text { Sinal } \\
\text { esperado }\end{array}$ \\
\hline $\begin{array}{l}\text { 1) Nível de inflação mais baixo } \\
\text { está associado a uma meta mais baixa }\end{array}$ & Inflação & + \\
2) Crescimento do produto mais baixo & $\Delta$ LPIB & - \\
está associado a uma meta mais alta & DBGG/PIB & + \\
3) Nível da DBGG/PIB mais baixo & & \\
está associado a uma meta mais baixa & $\Delta($ DBGG/PIB $)$ & + \\
4) Trajetória da DBGG/PIB decrescente & & - \\
está associada a uma meta mais baixa & Banda de tolerância permitem a es- & + \\
colha de uma meta mais baixa & Emergente & + \\
6) Países emergentes têm uma meta pa- & & \\
ra a inflação mais alta & &
\end{tabular}

\section{Capítulo 4}

\section{Resultados}

As estimações dos determinantes das metas para a inflação apresentadas neste capítulo baseam-se na evolução das pré-condições para a adoção do regime de metas. Estes fundamentos macroeconômicos são medidos pelas variáveis explicativas defasadas em um ano conforme explicado no capítulo 3 . 
A Tabela 4.1 mostra a primeira estimação para a equação (3.1) via Mínimos Quadrados Ordinários (MQO), efeito fixo (EF) e efeito aleatório (EA) para os 17 países que têm desvio padrão da meta maior que 0 a partir do ano de adoção do regime (ver coluna 7 da Tabela 3.1).

A inflação, como esperado, tem um forte impacto sobre as metas. Desta forma, se o banco central espera por uma inflação baixa e estável, reflexo do atual estado da economia, o anúncio da meta para os próximos anos estará associado a este patamar inflacionário.

O coeficiente obtido para a trajetória da dívida bruta/PIB ( $\Delta(\mathrm{DBGG} / \mathrm{PIB}))$ é significativo, porém com sinal contrário ao esperado. Já o coeficiente do estoque da dívida bruta/PIB (DBGG/PIB) tem efeito significante na definição das metas e sinal positivo, o que sugere que, uma política fiscal sustentável contribui para o declínio das metas.

A taxa de crescimento do PIB real ( $\Delta$ LPIB), proxy para crescimento de longo prazo, não tem efeito sobre a meta. Geralmente, economias com rápido crescimento econômico, característica comum a vários países emergentes, apresentam uma meta para a inflação superior àquela praticada pelos países avançados, segundo Mishkin and Schmidt-Hebbel (2000). Em 2003, o banco central da Polônia estabeleceu em relatório que suas estratégias de política monetária para escolher a meta para a inflação seria consistente com o crescimento econômico. ${ }^{1}$ Entretanto, este resultado não se verifica empiricamente neste trabalho.

Com a introdução das dummies, na Tabela 4.2, verifica-se que o coeficiente para dummy de bandas de tolerância (Banda) tem efeito significante e sinal negativo, demonstrando, assim, que se o país anuncia bandas, menor pode ser a meta para a inflação, indicando comprometimento com uma inflação baixa, porém flexibilidade para desviar do centro da meta quando necessário. Isto é analisado por Lohman (1992) por meio da introdução de cláusulas de escape na condução da política monetária em situações extremas. Já a dummy para emergentes (Emergente), proxy utilizada para qualidade dos fundamentos macroeconômicos, não tem efeito algum nas metas. Quanto à estimação do modelo mais apropriada, ao executar o teste de Hausman, verifica-se que o efeito fixo (coluna 2) é o mais indicado, tanto nas estimações apresentadas pela Tabela 4.1, quanto nas estimações apresentadas na Tabela 4.2.

Diferentemente das duas estimações anteriores, os resultados obtidos nas Tabelas 4.3 e 4.4 referem-se aos 17 países que apresentam desvio padrão da meta maior que 0 a partir do ano de 2000 (ver coluna 8 da Tabela 3.1) como forma de atenuar o desbalanceamento do painel estimado anteriormente. Os estimadores usados são os mesmos: Mínimos Quadrados Ordinários (MQO), efeito fixo (FE) e efeito aleatório (EA).

Os resultados são semelhantes às estimações apresentadas nas Tabelas 4.1 e 4.2, exceto pelo

\footnotetext{
${ }^{1}$ Ver Monetary Policy Strategy beyond 2003 - página 12.
} 
Tabela 4.1: Estimação dos Determinantes das Metas para a Inflação (a partir do ano de adoção do regime).

\begin{tabular}{lccc}
\hline \multicolumn{1}{c}{ Estimador } & MQO & EF & EA \\
Regressor & $(1)$ & $(2)$ & $(3)$ \\
\hline Inflação & $0.490^{* * *}$ & $0.449^{* * *}$ & $0.467^{* * *}$ \\
& $(11.48)$ & $(17.36)$ & $(18.72)$ \\
$\Delta$ LPIB & 0.024 & -0.029 & -0.005 \\
& $(0.71)$ & $(-0.98)$ & $(-0.15)$ \\
DBGG/PIB & 0.002 & $0.016^{*}$ & 0.004 \\
& $(0.51)$ & $(2.01)$ & $(0.73)$ \\
$\Delta$ (DBGG/PIB $)$ & -0.023 & $-0.072^{* *}$ & -0.046 \\
& $(-0.73)$ & $(-2.75)$ & $(-1.77)$ \\
Constante & $1.365^{* * *}$ & $1.153^{* *}$ & $1.550^{* * *}$ \\
& $(4.94)$ & $(3.14)$ & $(5.34)$ \\
\hline Observações & 279 & 279 & 279 \\
$R^{2}$ Ajustado & 0.603 & 0.542 & \\
\hline
\end{tabular}

Nota: Mínimos Quadrados Ordinários (MQO) na coluna 1, efeito fixo (EF) na coluna 2 e efeito aleatório (EA) na coluna 3. Estatística $t$ em pararênteses. Significâncias indicadas por $\left(^{*}\right) p-$ valor $<0.05,\left({ }^{* *}\right) p-$ valor $<0.01,\left({ }^{* * *}\right)$ $p-$ valor $<0.001$. Teste de Hausman, cujo $p-$ valor $=0.0002$, indica o EF como estimador mais apropriado a um nível de $5 \%$ de significância. Neste teste a hipótese nula estabelece como estimador preferido o EA vs a hipótese alternativa que estabelece como estimador preferido o EF.

Fonte: Estimações calculadas por software estatístico. 
Tabela 4.2: Estimação dos Determinantes das Metas para a Inflação: Dummies para Bandas de Tolerância e para Países Emergentes (a partir do ano de adoção do regime).

\begin{tabular}{lccc}
\hline \multicolumn{1}{c}{ Estimador } & MQO & EF & EA \\
Regressor & $(1)$ & $(2)$ & $(3)$ \\
\hline Inflação & $0.451^{* * *}$ & $0.411^{* * *}$ & $0.428^{* * *}$ \\
& $(9.72)$ & $(15.92)$ & $(16.49)$ \\
$\Delta$ LPIB & 0.021 & -0.031 & -0.010 \\
& $(0.66)$ & $(-1.10)$ & $(-0.33)$ \\
DBGG/PIB & 0.003 & $0.017^{*}$ & 0.00484 \\
& $(0.62)$ & $(2.26)$ & $(0.91)$ \\
$\Delta$ (DBGG/PIB) & -0.025 & $-0.077^{* *}$ & $-0.0520^{*}$ \\
& $(-0.82)$ & $(-3.08)$ & $(-2.05)$ \\
Banda & $-0.768^{*}$ & $-1.290^{* * *}$ & $-0.982^{* * *}$ \\
& $(-2.58)$ & $(-5.01)$ & $(-3.99)$ \\
Emergente & 0.216 & & 0.234 \\
& $(1.22)$ & & $(0.81)$ \\
Constante & $2.033^{* * *}$ & $2.379^{* * *}$ & $2.369^{* * *}$ \\
& $(5.06)$ & $(5.56)$ & $(5.43)$ \\
\hline Observações & 279 & 279 & 279 \\
$R^{2}$ Ajustado & 0.617 & 0.581 & \\
\hline
\end{tabular}

Nota: Mínimos Quadrados Ordinários (MQO) na coluna 1, efeito fixo (EF) na coluna 2 e efeito aleaório (EA) na coluna 3. Estatística $t$ em pararênteses. Significâncias indicadas por $\left({ }^{*}\right) p-$ valor $<0.05,\left({ }^{* *}\right) p-$ valor $<0.01,\left({ }^{* * *}\right)$ $p-$ valor $<0.001$. Teste de Hausman, cujo $p-$ valor $=0.0000$, indica o EF como estimador mais apropriado a um nível de $5 \%$ de significância. Neste teste a hipótese nula estabelece como estimador preferido o EA vs a hipótese alternativa que estabelece como estimador preferido o EF.

Fonte: Estimações calculadas por software estatístico. 
Tabela 4.3: Estimação dos Determinantes das Metas para a Inflação (período entre 2000-2016).

\begin{tabular}{lccc}
\hline \multicolumn{1}{c}{ Estimador } & MQO & EF & EA \\
Regressor & $(1)$ & $(2)$ & $(3)$ \\
\hline Inflação & $0.352^{* * *}$ & $0.218^{* * *}$ & $0.272^{* * *}$ \\
& $(10.65)$ & $(8.49)$ & $(10.82)$ \\
$\Delta$ LPIB & -0.017 & $-0.063^{* *}$ & -0.045 \\
& $(-0.51)$ & $(-2.76)$ & $(-1.87)$ \\
DBGG/PIB & -0.001 & -0.006 & -0.004 \\
& $(-0.39)$ & $(-0.74)$ & $(-0.84)$ \\
$\Delta$ (DBGG/PIB) & -0.012 & -0.039 & -0.0290 \\
& $(-0.47)$ & $(-1.97)$ & $(-1.41)$ \\
Constante & $2.129^{* * *}$ & $2.991^{* * *}$ & $2.744^{* * *}$ \\
& $(8.60)$ & $(8.24)$ & $(9.59)$ \\
\hline Observações & 247 & 247 & 247 \\
$R^{2}$ Ajustado & 0.456 & 0.198 & \\
\hline
\end{tabular}

Nota: Mínimos Quadrados Ordinários (MQO) na coluna 1, efeito fixo (EF) na coluna 2 e efeito aleatório (EA) na coluna 3. Estatística $t$ em pararênteses. Significâncias indicadas por $\left({ }^{*}\right) p-$ valor $<0.05,\left({ }^{* *}\right) p-$ valor $<0.01,\left({ }^{* * *}\right)$ $p-$ valor $<0.001$. Teste de Hausman, cujo $p-$ valor $=0.0000$, indica o EF como estimador mais apropriado a um nível de $5 \%$ de significância. Neste teste a hipótese nula estabelece como estimador preferido o EA vs a hipótese alternativa que estabelece como estimador preferido o EF.

Fonte: Estimações calculadas por software estatístico.

estoque da dívida bruta, pela taxa de crescimento do produto real ( $\Delta$ LPIB) e pela dummy para emergentes (Emergente). Em relação à primeira, os resultados apontam que não existe uma relação significativa entre o estoque da dívida e metas para a inflação. Para a segunda, obtevese uma estimativa estatisticamente significante a um nível de $1 \%$ de significância com sinal conforme o esperado, ou seja, existe uma relação negativa entre metas e crescimento econômico de longo prazo. Já a terceira, dummy para emergentes (Emergentes), proxy para a qualidade dos fundamentos macroeconômicos, apresenta significância e sinal positivo, corroborando a hipótese de que se o país for emergente, a meta para a inflação é maior, visto que, países emergentes, geralmente, apresentam maior falta de maturidade institucional e inconsistência dos fundamentos macroeconômicos que afetam, por sua vez, a estratégia e condução de política monetária.

Quanto ao método de estimação mais apropriado, o teste de Hausman indica que é o de efeito fixo (ver coluna 2), tanto nas estimações apresentadas pela Tabela 4.3, quanto nas estimações apresentadas pela Tabela 4.4 
Tabela 4.4: Estimação dos Determinantes das Metas para a Inflação: Dummies para Bandas de Tolerância e para Países Emergentes (período entre 2000-2016).

\begin{tabular}{lccc}
\hline \multicolumn{1}{c}{ Estimador } & MQO & EF & EA \\
Regressor & $(1)$ & $(2)$ & $(3)$ \\
\hline Inflação & $0.278^{* * *}$ & $0.185^{* * *}$ & $0.203^{* * *}$ \\
& $(9.74)$ & $(7.95)$ & $(8.53)$ \\
$\Delta$ LPIB & -0.017 & $-0.055^{* *}$ & $-0.046^{*}$ \\
& $(-0.55)$ & $(-2.75)$ & $(-2.19)$ \\
DBGG/PIB & -0.002 & 0.003 & -0.003 \\
& $(-0.55)$ & $(0.38)$ & $(-0.52)$ \\
$\Delta$ (DBGG/PIB) & -0.009 & $-0.042^{*}$ & -0.031 \\
& $(-0.35)$ & $(-2.44)$ & $(-1.72)$ \\
Banda & $-1.011^{* * *}$ & $-1.647^{* * *}$ & $-1.425^{* * *}$ \\
& $(-3.96)$ & $(-7.84)$ & $(-6.93)$ \\
Emergente & $0.557^{* * *}$ & & $0.808^{* *}$ \\
& $(4.60)$ & & $(2.83)$ \\
Constante & $2.919^{* * *}$ & $4.207^{* * *}$ & $3.617^{* * *}$ \\
& $(8.96)$ & $(11.75)$ & $(9.37)$ \\
\hline Observações & 247 & 247 & 247 \\
$R^{2}$ Ajustado & 0.525 & 0.368 & \\
\hline
\end{tabular}

Nota: Mínimos Quadrados Ordinários (MQO) na coluna 1, efeito fixo (EF) na coluna 2 e efeito aleatório (EA) na coluna 3. Estatística $t$ em pararênteses. Significâncias indicadas por $\left({ }^{*}\right) p-$ valor $<0.05,\left({ }^{* *}\right) p-$ valor $<0.01,\left({ }^{* * *}\right)$ $p-$ valor $<0.001$. Teste de Hausman, cujo $p-$ valor $=0.0000$, indica o EF como estimador mais apropriado a um nível de $5 \%$ de significância. Neste teste a hipótese nula estabelece como estimador preferido o EA vs a hipótese alternativa que estabelece como modelo preferido o $\mathrm{EF}$.

Fonte: Estimações calculadas por software estatístico. 
Finalmente, para considerar todos os países da amostra, utiliza-se os dados cross-section e estima-se via Mínimos Quadrados Ordinários (MQO) os determinantes das metas para a inflação, ano a ano, a partir de 2000 até 2016. Os coeficientes e intervalos de confiança para cada variável explicativa podem ser vistos nas Figuras A.1 à A.6 no apêndice. Observa-se que os coeficientes obtidos ano a ano para a inflação são todos significativos e apresentam sinal positivo, corroborando mais uma vez a hipótese de que um nível elevado de inflação está associado a uma meta mais alta. A dummy para emergentes (Emergente), proxy para qualidade dos fundamentos macroeconômicos, apresenta significância e sinal positivo, conforme esperado, na maioria dos anos. No entanto, a taxa de crescimento do PIB real ( $\Delta$ LPIB), o estoque da dívida bruta/PIB (DBGG/PIB), o fluxo da dívida bruta $(\Delta(\mathrm{DBGG} / \mathrm{PIB}))$ e a dummy para bandas de tolerância (Banda) apresentam resultados ambíguos em relação ao sinal esperado para os coeficientes.

\section{Capítulo 5}

\section{Conclusão}

Com base no modelo de Araujo et al. (2016), este trabalho analisa como a meta para a inflação é definida pelos países que adotam o regime de metas para a inflação. Esta questão é pouco explorada pela academia, embora mesmo entre os países que adotam o regime de metas, há diferenças quanto ao valor numérico da meta, principalmente quando comparados por grupos de países avançados e de países emergentes.

À luz dos estudos empíricos que analisam a capacidade que um país tem em alcançar a meta, as variáveis explicativas escolhidas como possíveis determinantes das metas capturam, em certa medida, o estado da economia, como a inflação, dívida bruta/PIB e a taxa de crescimento do PIB real. Por fim, entende-se que, em geral, países emergentes apresentam fundamentos piores em relação aos países avançados.

Para estimar os determinantes das metas, utiliza-se os dados em painel e os dados crosssection. Verifica-se que um nível de preços estável está associado a uma meta mais ambiciosa, assim como a adoção de bandas de tolelarância contribui para uma meta pontual mais baixa.

Em relação ao estoque da dívida bruta, os resultados para a amostra com maior número de 
observações sugerem que existe uma relação positiva significativa com as metas para a inflação. Porém, para a amostra com menor número de observações, esta relação não se verifica. Além disto, para o fluxo da dívida bruta, os resultados mostram sinal contrário ao esperado em todas as estimações, sendo significativo exceto para a estimação com menor número de observações que não inclui as variáveis dummies. Desta forma, não se pode afirmar que há uma relação entre solvência fiscal e metas baixas. Ainda, os resultados sugerem que não há evidências de coordenação entre políticas monetária e fiscal para os países analisados, em sua maioria, países emergentes, pois um aumento da dívida bruta/PIB (fluxo), piora os fundamentos, porém o banco central estipula uma meta mais baixa.

Quanto à proxy para crescimento econômico de longo prazo, os resultados das estimações com menor número de observações apontam que há uma relação negativa significante entre esta última e metas para a inflação.

Sendo assim, conclui-se que as metas para a inflação têm correlação com alguns fundamentos macroeconômicos. Isto porque países que possuem um crescimento alto e robusto e inflação baixa escolhem uma meta mais ambiciosa. Logo, por medidas como estas, há evidências de gradualismo na política monetária. 


\section{Referências Bibliográficas}

F. Andersson and L. Jonung. How tolerant should inflation targeting central banks be? Selecting the proper tolerance band - Lessons from Sweden. Working Paper - Lund University, 2017.

GM. Angeletos and I. Werning. Crises and prices: information aggregation, multiplicity and volatility. American Economic Review, (96), 2006.

A. Araujo, T. Berriel, and R Santos. Inflation targeting with imperfect information. International Economic Review, 57:255-270, 2016.

L. Ball and N. Sheridan. Does inflation targeting matter? The inflation targeting debate. The University of Chicago Press, Chicago, pages 249-276, 2005.

R. Barro and D. Gordon. Rules, discretion and reputation in a model of monetary policy. Journal of Monetary Economics, 12:101-121, 1983.

M. Beechey and P. Osterholmb. Forecasting inflation in an inflation-targeting regime: a role for informative steady-state priors. International Journal of Forecasting, pages 248 -264, 2010.

B Bernanke and F Mishkin. Inflation targeting: a new framework for monetary policy? The Journal of Economic Perspectives, 11(2):97-116, 1997.

B. Bernanke and M. Woodford. Introduction. The inflation targeting debate, The University of Chicago Press, pages 1-10, 2005.

R. Billy and G. Kahn. What is the optimal inflation rate? Federal Reserve Bank of Kansas City, 2008.

O. Blachard. Macroeconomics. Pearson Prentice Hall, (4th edition), 2007.

H. Bohn. Are stationarity and cointegration restrictions really necessary for the intertemporal budget constraint? Journal of Monetary Economics, page 18371847, 2007.

R. Brito and B. Bystedt. Inflation targeting in emerging economies: panel evidence. Journal of Development Economics, 91:198-210, 2010. 
R. Caballero and A. Krishnamurthy. Inflation targeting and sudden stops. The inflation targeting debate, The University of Chicago Press, pages 423-442, 2005.

G. Calvo and F. Mishkin. The mirage of exchange rate regimes for emerging market countries. Journal of Economic Perspectives, 2003.

A. Carvalho and C. Gonçalves. Inflation targeting matters: evidence from OECD economies's sacrifice ratios. Journal of Money, Credit and Banking, 41:233-243, 2007.

R. Clarida, J. Gali, and M. Gertler. The science of monetary policy - a new keynesian perspective. National Bureau of Economic Reserarch, (7147), 1999.

A. Cukierman and S. Gerlach. The inflation bias revisited: theory and some internacional evidence. The Manchester School, 71(5):541-565, 2003.

FMI. Does inflation targeting work in emergent markets? Washington, 11(2):97-116, 2005.

C Gonçalves and A Carvalho. Who chooses to inflation target? Economics Letters, 99:410-413, 2008.

C Gonçalves and J. Salles. Inflation targeting in emerging economies: what do the data say? Journal of Development Economics, 85:312-318, 2008.

G. Hammond. State of the art of inflation targeting. Centre for Central Banking Studies, Handbook, Bank of England., (29), 2012.

G. Heenan, Marcel P., and R. Scott. Implementing inflation targeting: institutional arrangements, target design, and communications. IMF Working Paper, 2006.

J. Jonas and F. Mishkin. Inflation targeting in transition economies experience and prospects. National Bureau of Economic Reserarch, (9667):1720-1736, 2003.

H. Kim and J. Kim. Inflation targeting in practice: korean experience. Kobe University Economic Review, 55, 2009.

M. Kumhof, R. Nunes, and I. Yakadina. Simple monetary rules under fiscal dominance. Journal of Money, Credit and Banking, (1), 2010.

F. Kydland and E. Prescott. Rules rather than discretion: the inconsistency of optimal plans. Journal of Political Economy, 85(3):473-492, 1977.

S. Lohman. Optimal commitment in monetary policy: credibility versus flexibility. American Economic Review, (82):273-286, 1992. 
R. Lucas and T. Sargent. After keynesian macroeconomics. Federal Reserve Bank of Minneapolis, 1979.

F. Mishkin. Inflation targeting in emerging market countries. American Economic Review Papers and Proceedings, pages 105-109, 2000.

F. Mishkin. Can inflation targeting work in emerging market countries? NBER Working Paper Series, 10646, 2004.

F. Mishkin and K. Schmidt-Hebbel. A decade of inflation targeting in the world: what do we know and what do we need to know? Central Bank of Chile, 2000.

S. Morris and H. Shin. Rethinking multiple equilibria in macroeconomic modeling. in NBER Macroeconomics Annual 2000, pages 139-182, 2001.

K. Rogoff. The optimal degree of commitment to an intermediate monetary target. The Quarterly Journal of Economics, pages 1169-1189, 1985.

H. Samaryna and J. Haan. Right on target: exploring the determinants of inflation targeting adoption. DNB Working Paper, (321), 2011.

T. Sargent and N. Wallace. Some unpleasant monetarist arithmetic. Quarterly Review of the Minneapolis Federal Reserve Bank, 1987.

C. Sims. Limites to inflation targeting. The inflation targeting debate, The University of Chicago Press, 2005.

L. Svensson. Optimal inflation targets, conservative central banks, and linear inflation contracts. American Economic Review, (1):98-114, 1997.

L. Svensson. Inflation targeting as a monetary policy rule. Journal of Monetary Economics, pages 607-654, 1999.

C. Walsh. Optimal contracts for central bankers. American Economic Review, (1):150-167, 1995. 


\section{Apêndice A}

\section{Apêndice}

Figura A.1: Estimação dos Determinantes das Metas para a Inflação - Coeficientes obtidos ano a ano para a inflação.

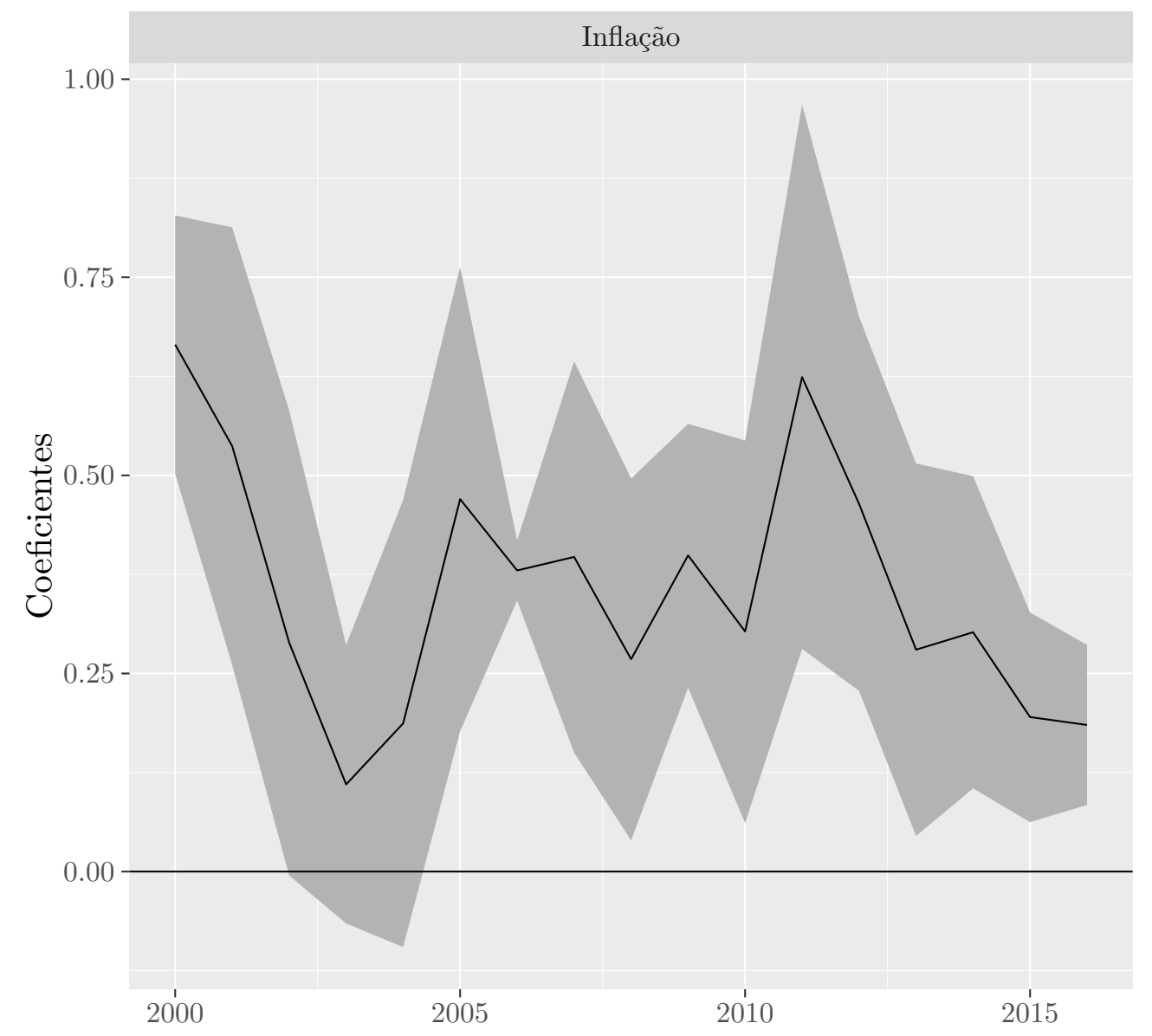

Nota: Parâmetros estimados ano a ano e seus intervalos de confiança (95\%). Fonte: Estimações calculadas por software estatístico. 
Figura A.2: Estimação dos Determinantes das Metas para a Inflação - Coeficientes obtidos ano a ano para a taxa de crescimento do produto real.

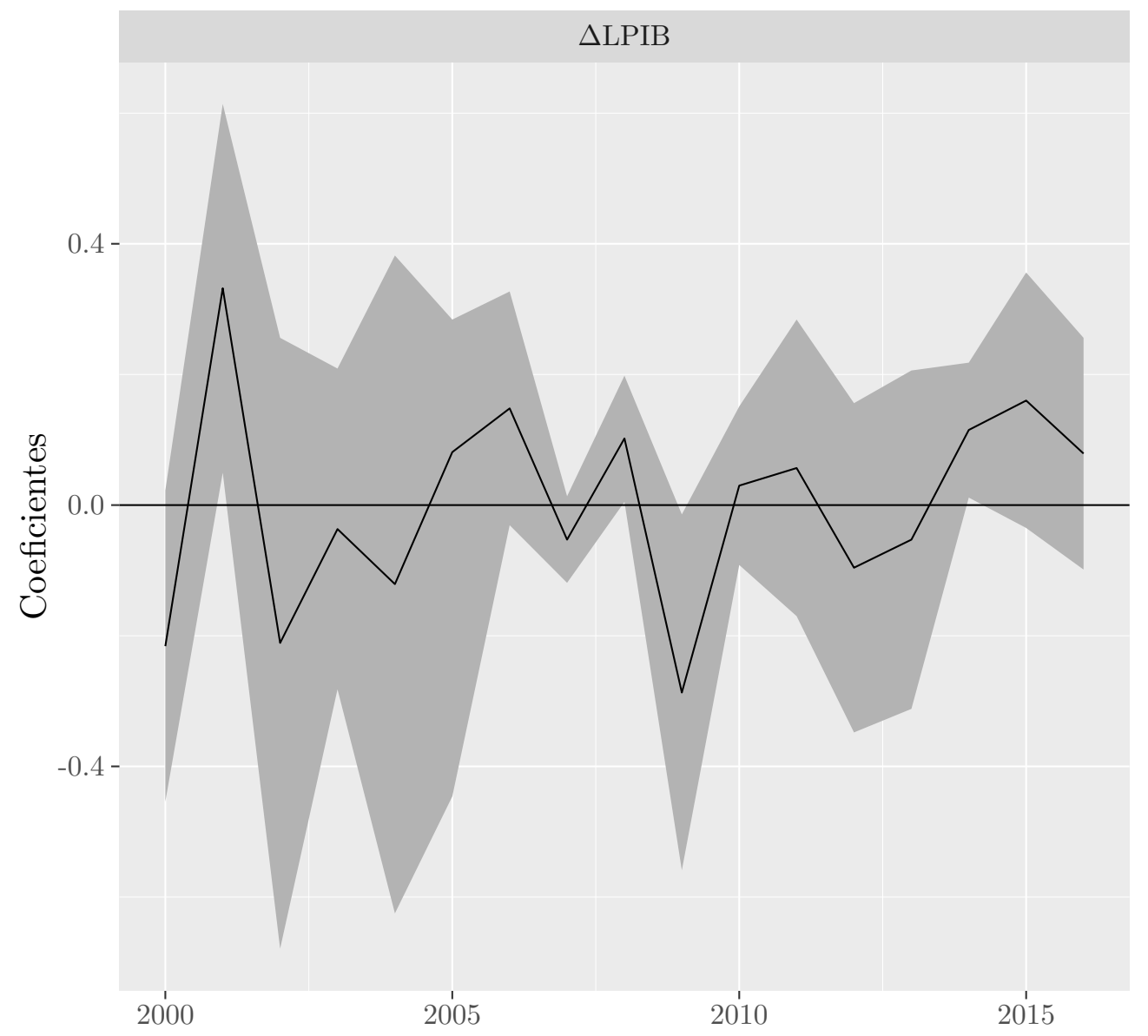

Nota: Parâmetros estimados ano a ano e seus intervalos de confiança (95\%). Fonte: Estimações calculadas por software estatístico. 
Figura A.3: Estimação dos Determinantes das Metas para a Inflação - Coeficientes obtidos ano a ano para o estoque da dívida bruta.

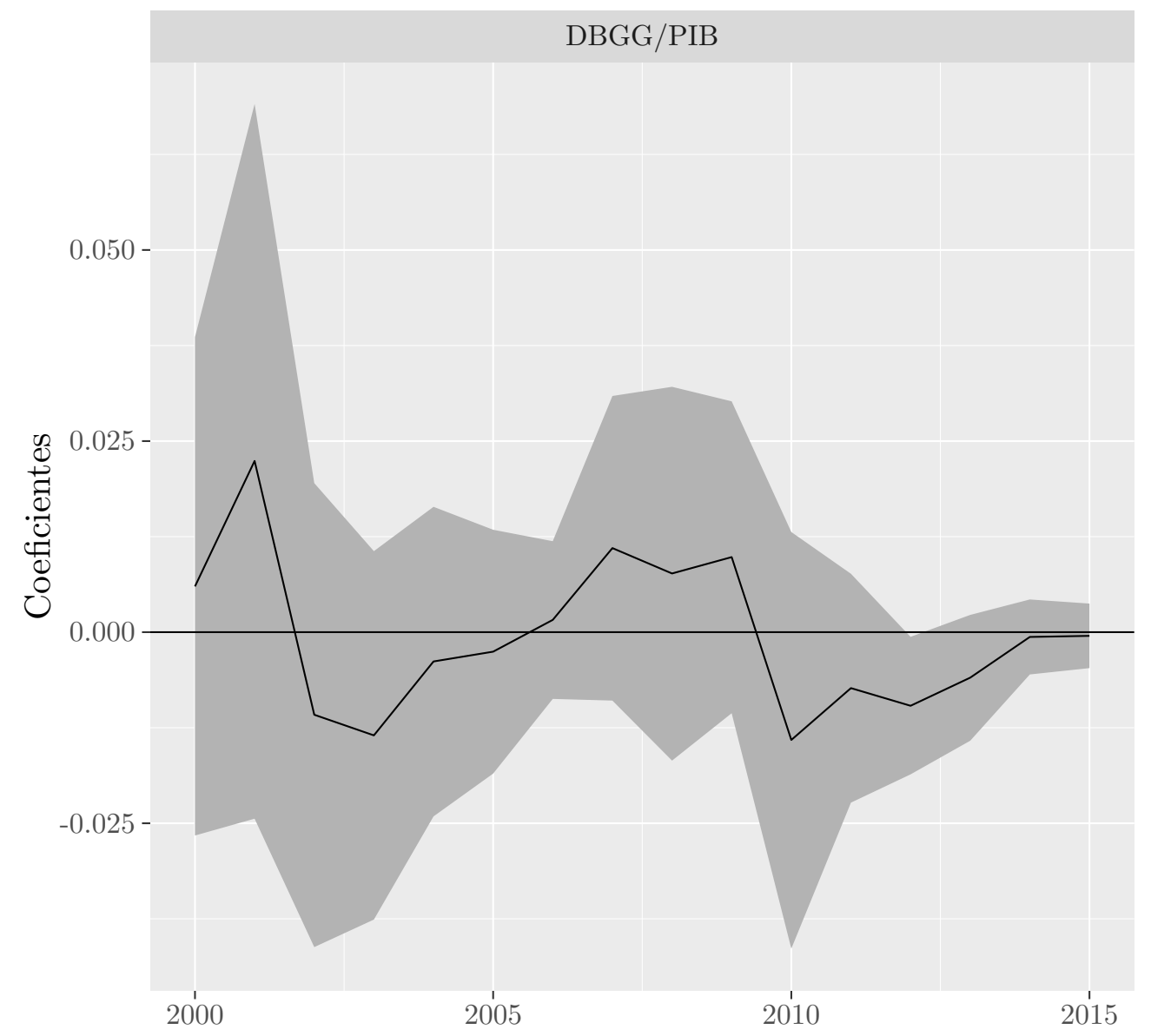

Nota: Parâmetros estimados ano a ano e seus intervalos de confiança (95\%). Fonte: Estimações calculadas por software estatístico. 
Figura A.4: Estimação dos Determinantes das Metas para a Inflação - Coeficientes obtidos ano a ano para o fluxo da dívida bruta.

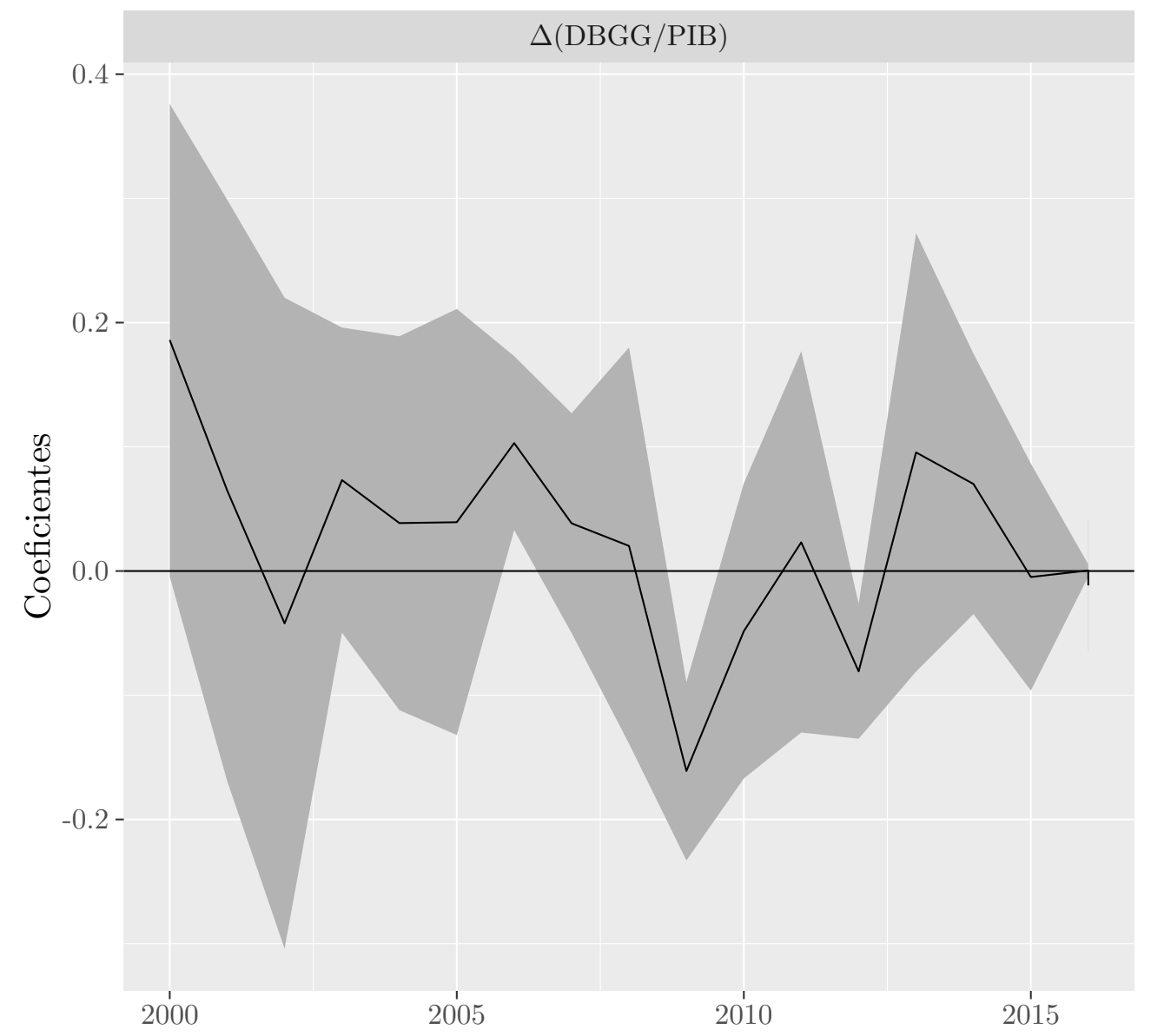

Nota: Parâmetros estimados ano a ano e seus intervalos de confiança (95\%). Fonte: Estimações calculadas por software estatístico. 
Figura A.5: Estimação dos Determinantes das Metas para a Inflação - Coeficientes obtidos ano a ano para a dummy de bandas de tolerância.

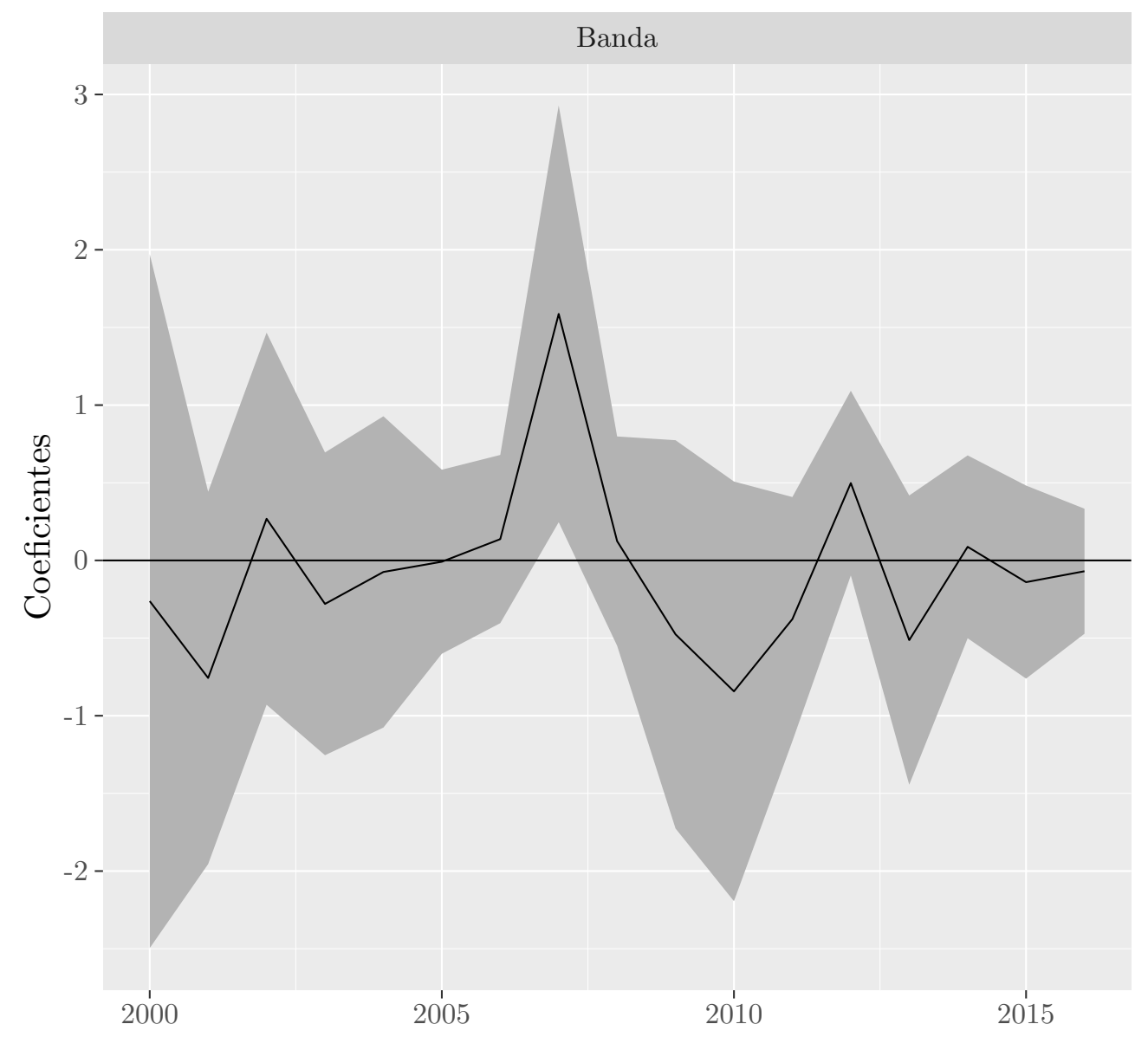

Nota: Parâmetros estimados ano a ano e seus intervalos de confiança (95\%). Fonte: Estimações calculadas por software estatístico. 
Figura A.6: Estimação dos Determinantes das Metas para a Inflação - Coeficientes obtidos ano a ano para a dummy de países emergentes.

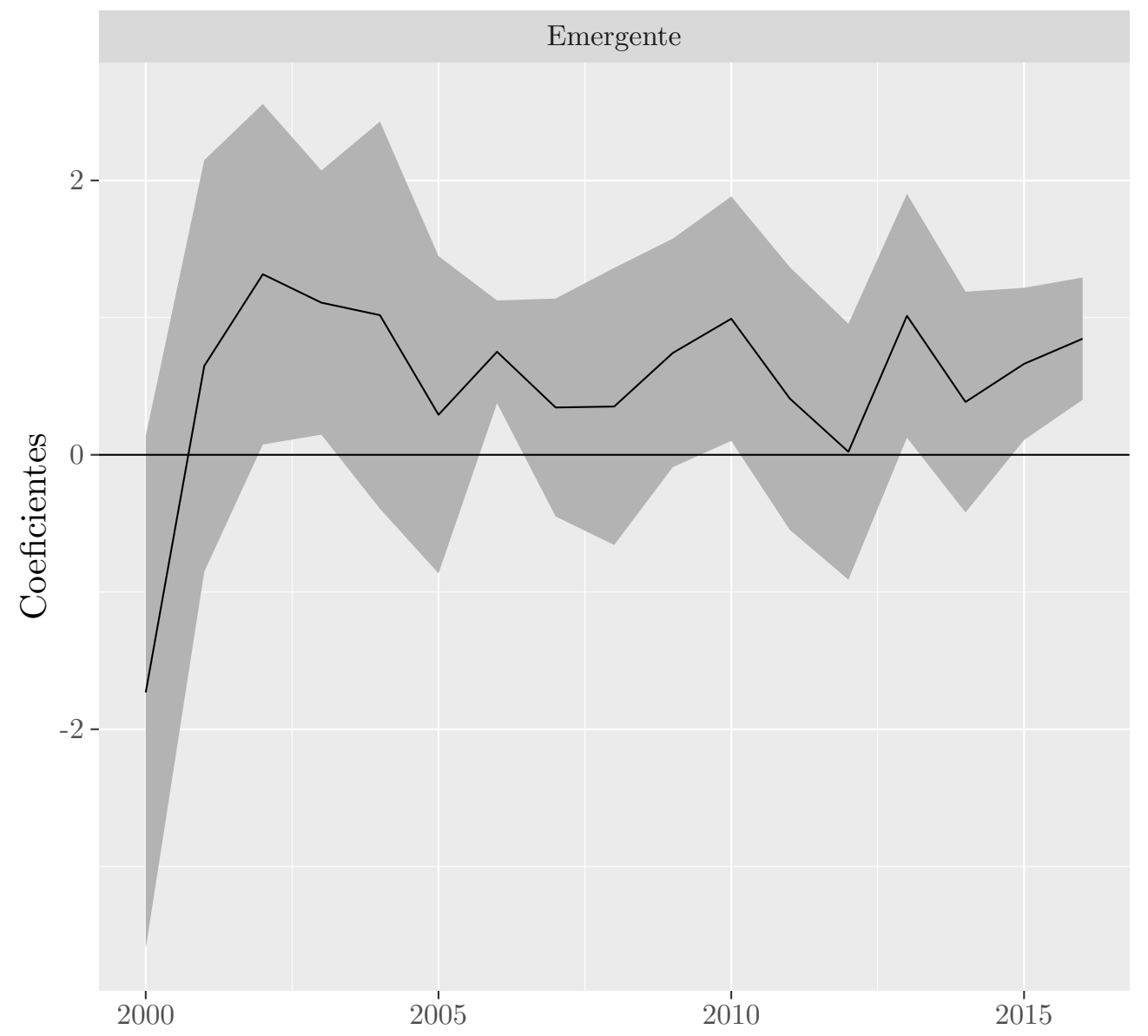

Nota: Parâmetros estimados ano a ano e seus intervalos de confiança (95\%). Fonte: Estimações calculadas por software estatístico. 